\title{
Design of Online Bidding Management System
}

\author{
shuli Huang \\ College of Information Engineering, Jiangxi University of Technology, Jiangxi Nanchang
}

Keywords: Online bidding; Management information system; Information technology; Bidding

\begin{abstract}
In order to provide a wide communication platform and reduce the blindness of the transaction between the bidder and the tenderer, the design for online tender management system was born. Firstly, this paper focuses on the requirement analysis; secondly, it expounds the designs of database and system; Lastly, it carries out the test to the system. The design system in this paper helps the mutual reactions between various partners come true,such as suppliers, bidding mechanism, evaluation experts, government supervision agencies and so on. In this new system there are following features : enterprises, institutions and individuals deliveries the bidding database online; besides, evaluation of the bid and the bid opening are also manipulated through the network, finally enterprises and the public withdraw the bidding results from the internet.
\end{abstract}

\section{Overview}

In the developed countries of Europe and American, The online bidding championing the electronic procurement has been widely used and formed a relatively mature business operating mode. The online bidding has been successfully implemented in lots of government organizations and many enterprises. Only federal Department of general affairs purchasing materials through online bidding amounts to as high as $\$ 10$ billion each year. Each year, the Singapore government through "government electronic commerce center" . The value of purchasing products has reached $\$ 1.1$ billion. In the future, there will be $80 \%$ of government procurement are transfer to "government electronic commerce center".

American GM, Ford and Daimler - Chrysler---the three big auto companies jointly established the auto parts procurement network"COVISINT", it used to support collaborative work of the automotive industry and to achieve the globalization of procurement; Through the project of E - procurement, HP enhanced the management of liquidity and supply chain, then the procurement costs fell down by $17 \%$, inventory turnover rate was increased by $60 \%$, and customer order cycle was cut in half. Before the end of 2004, electronic procurement system had save $\$ 600$ million in procurement funds for HP. With the implementation of " the bidding act", China has been vigorously promoting the bidding system. Because of online bidding owning some remarkable advantages over the traditional way, the Chinese government has absorbed the online bidding procurement into the e-government system, some government departments have begun to use the new way for online public procurement.

In addition, some of the larger bidding agencies have developed their own bidding sites and systems. Currently There are some excellent online bidding websites such as: Chinese government procurement network, Chinese International Bidding network, Chinese online bidding, Chinese tendering and bidding network, Chinese procurement and bidding network, 
government procurement portal - e financial network and so on. In addition, a lot of local government in the process of e-government construction has also developed a number of government specialized procurement websites. Although China has an abundant supply of online bidding websites, most of them have a single function, only provide the bidding information's originated sites. As a result, they mainly serves as an information exchange platform for tenderers and bidders, however, they can never be called a "bidding system". To certain extent, these systems have realized the bidding activities electronically, they did not integrate the core elements such as :bidding, bid evaluation, bid opening into the electronic system, furthermore, they didn't emancipate from the varied traditional human influence on bidding, Therefore, These systems are utterly far from the standard of a complete function online bidding and tender systems. In fact, the functions of online bidding include online issuing of biding documents, online bidding, the opening and evaluation of bidding, online purchase transactions and contracting and so on, It is a rather complicated process, not as easy as the online releasing information and downloading the bidding documents.

\section{The analysis of needs}

The feasibility analysis of the system. The function feasibility

This system chiefly keeps an accurate record and management of the product, the manufacturer and the project appropriately, which can basically satisfy the need of clients. In the system, the administrators have an easy access to the elaborate recordings and carry out information modification and removal.Therefore, it functions fully and independently. This will enable the tender to learn more detailed information about the bidder under the framework .It is openness, justice and fairness. Thus, this system is feasible.

The software's feasibility

This system refers to these software facilities :Windows XP Profession operating system,SQL Server 2000 database,Dreamweaver MX 2004code editing software, all of these are available.

The hardware's feasibility

The system is not very high for the hardware's requirements. Therefore, the normal internal storage and hard disk can conform .

The market's feasibility

The online bidding information management system can help the tenders find the bidders' cost interval effectively. therefore, they can have more choices and shorten the circulation of the bidding, so this kind of background management system application is expanding gradually .So the tenders' benefits are from the shortening period of the tendering and saving money, materials,and manpower. At the same time, the bidders play a better performance in a fairer platform as possible as they can.

The system mainly deals with the preservation, consultation ,revision and deletion of the information for the projects, manufacturers and the products. This system mainly designed according to the above functions, it concentrates on the reading and operation information. The customer interface includes product information, project information and vendor information. The project information includes the project name, the project time, the unit responsible for the 
project, the total project cost, the project introduction and so on. The vendor information contains the name of the bidding vendor, the address of the headquarters, the registered time, the registered address, the registered capital, the name of the legal person and details of the company. Except for the above information, the detailed information also refers to the branch agencies, branch offices and branch offices contact list, manufacturers in China or information of agents. Management interface is mainly for information management and project management. The main function are adding and deleting.

Data object analysis. According to the analysis of the relationship between the above data structure design and data items, you can get the needs of the various entities for users and the relationship between entities, This lays the foundation for the design of database logic structure. These entities contain a variety of specific information, The flow of data is formed through the interaction. The entities of the system are: administrator's information entities, general user's information entities, project information entities, equipment category information entities, manufacturers entity information, products information entities, Quotation information entity.

The main attribute diagram of the project entity is shown in Fig.1.

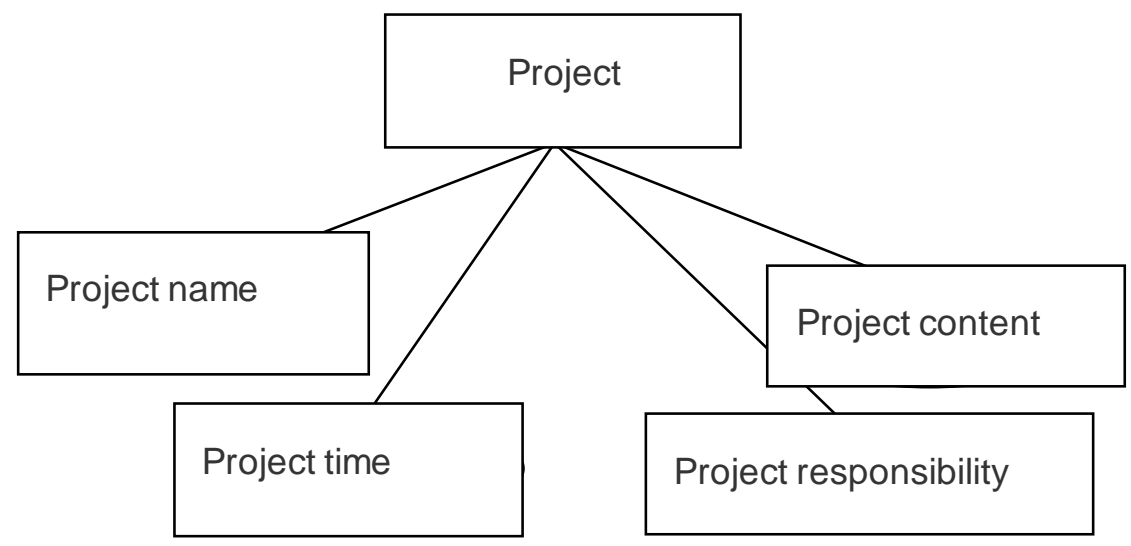

Fig. 1 Project entity diagram

Equipment category entity property diagram is shown in Fig. 2.

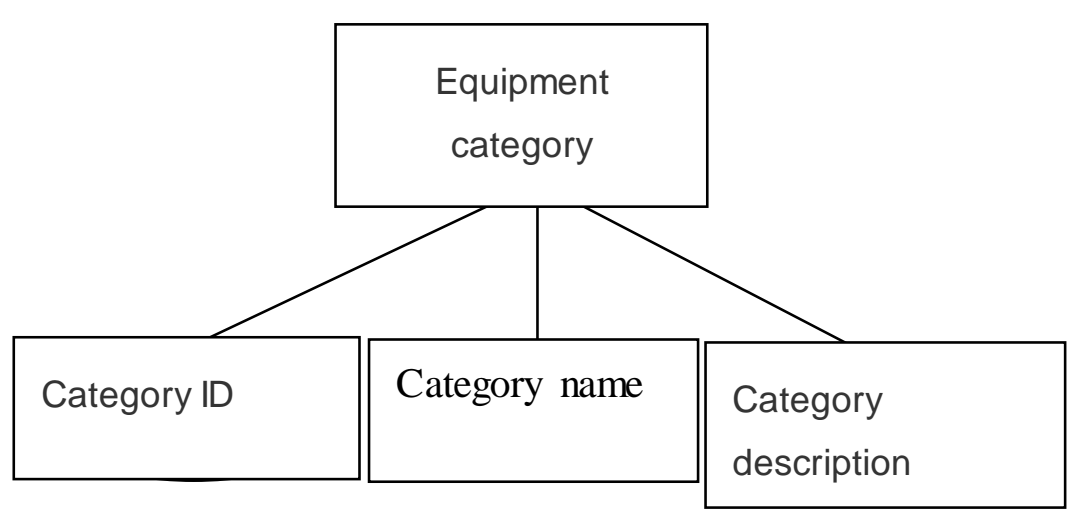

Fig. 2 device class entity diagram 
Vendor entity main property diagram, as shown in Fig. 3.

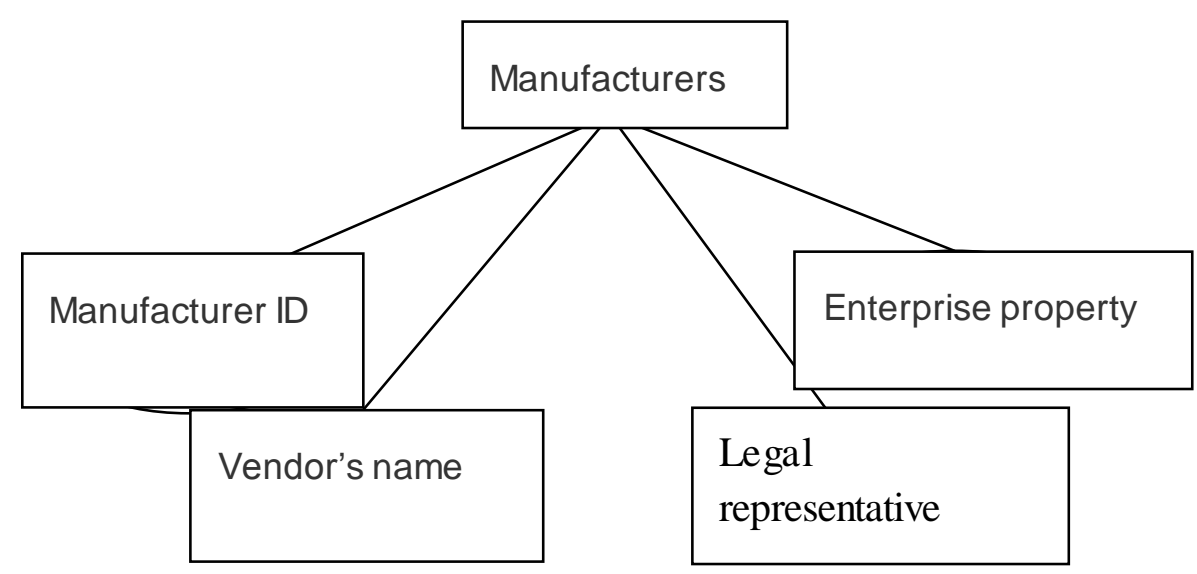

Fig. 3 vendor entity diagram

Product entity's main attribute graph

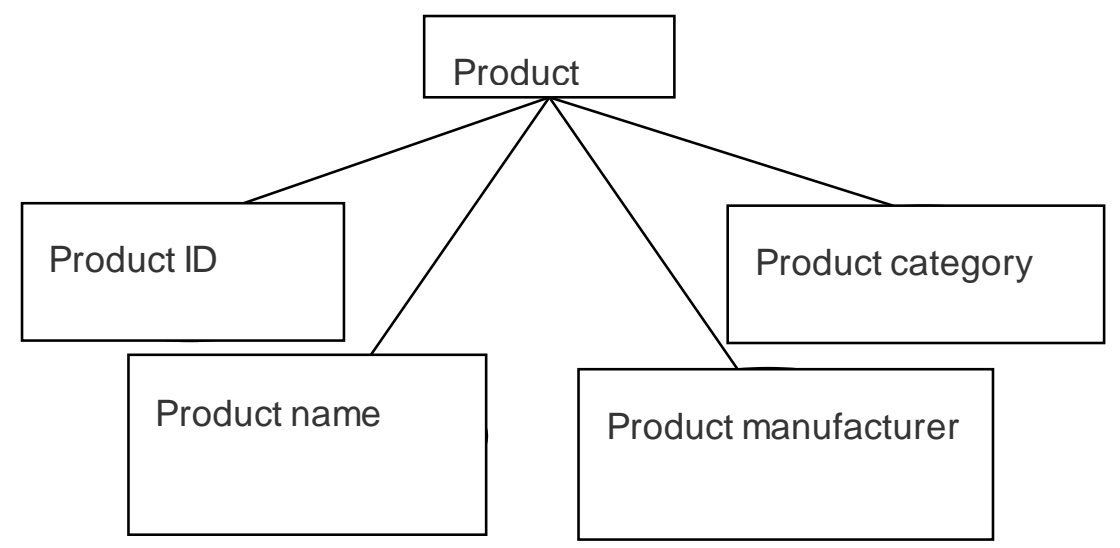

Fig. 4 product entity diagram

The main attribute chart of the bid entity is shown in Fig.5. 


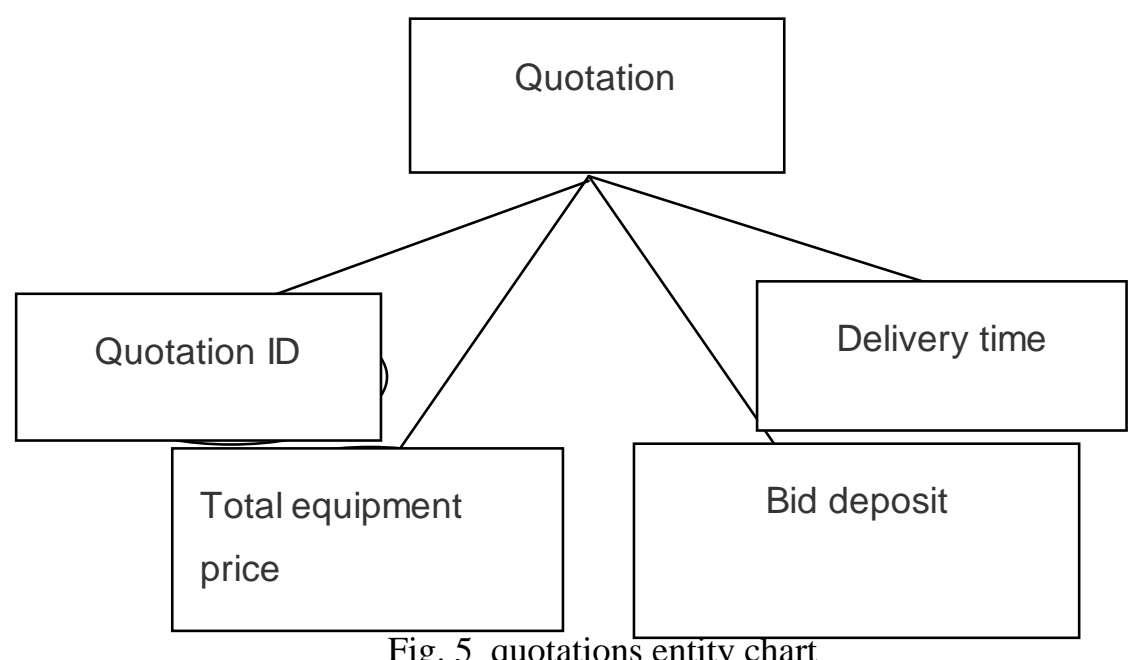

E-R between entities is shown in Fig. 6 .

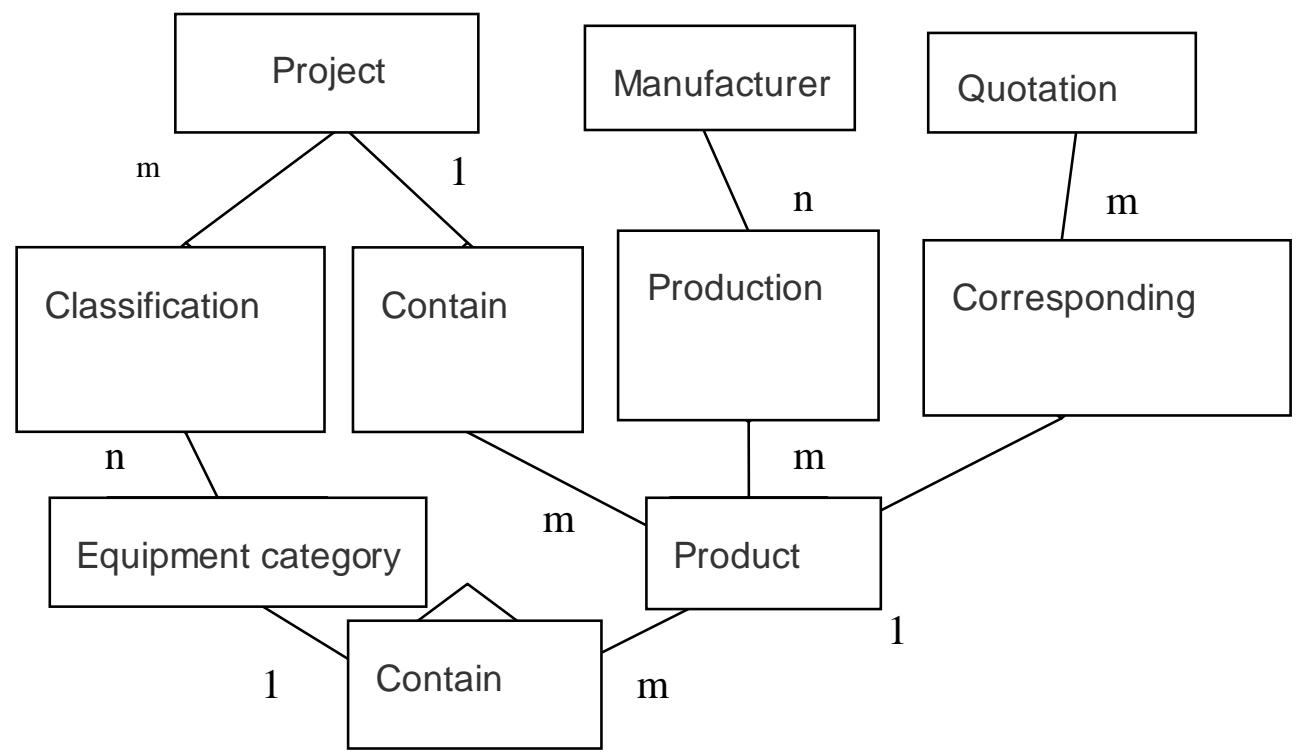

Fig. 6 entity E-R diagram

The contact of the data information in this system, such as Table1.

Table 1 data classes and functions

\begin{tabular}{|c|l|l|}
\hline Name & Use place and mode & Content description \\
\hline DBConnectionManager & $\begin{array}{l}\text { Connect with the } \\
\text { database }\end{array}$ & Database connection pool \\
\hline MakerManager & $\begin{array}{l}\text { Client query vendor } \\
\text { information }\end{array}$ & Including vendor query information \\
\hline NewMaker & $\begin{array}{l}\text { Management vendor } \\
\text { information }\end{array}$ & Manufacturers add, modify, delete \\
\hline ProjectManager & $\begin{array}{l}\text { Client query project } \\
\text { information }\end{array}$ & $\begin{array}{l}\text { Including query information for various } \\
\text { projects }\end{array}$ \\
\hline
\end{tabular}




\begin{tabular}{|c|c|c|}
\hline NewProject & $\begin{array}{l}\text { project information of } \\
\text { management }\end{array}$ & Project's add, modify and delete \\
\hline ProductManager & $\begin{array}{c}\text { The client's product } \\
\text { information }\end{array}$ & Including information on various products \\
\hline NewProduct & $\begin{array}{l}\text { product information of } \\
\text { management }\end{array}$ & Project's add, modify and delete \\
\hline New Type & $\begin{array}{l}\text { Management of class } \\
\text { management }\end{array}$ & Including add, modify and delete \\
\hline Basic & 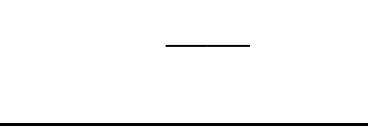 & $\begin{array}{l}\text { Get more than a few data object classes } \\
\text { according to ID }\end{array}$ \\
\hline Search & Client search & Vendor, project, product inquiry \\
\hline New Price & $\begin{array}{l}\text { Quotation management } \\
\text { for management }\end{array}$ & Add, modify, delete \\
\hline NewPPM & - & $\begin{array}{l}\text { Realize the relationship between the project, } \\
\text { the product and the manufacturer }\end{array}$ \\
\hline Db.properties & 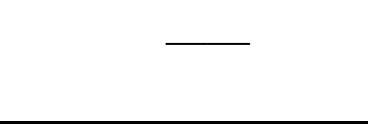 & $\begin{array}{l}\text { Configuration JDBC driver and connection } \\
\text { pool file }\end{array}$ \\
\hline
\end{tabular}

Establishment of system function model. The function of the system is to save, consult, modify and delete the information of the project, manufacturer and product. for this system is designed mainly for these information, so the function is mainly concentrate on the reading and operating the information.

Users can access to the relevant information in time through the system. there are two ways in specific: one is through the search engine ,entering keywords directly, the system search the database and search results returned; another way, The user research and browse the information step by step in the information page directly.

The main functions of this system are as follows:

1. customer interface part: product information query, vendor information query, project information query, comprehensive information query.

2. management interface part:project management and vendor management.

Customer interface can access to the external network, while management one just access to the intranet. The two terminal networks manipulate a common database. Due to the network's constraints, the external can not access to the management interface, in the management interface, there is only the function of administrator login and control information .

\section{Database outline design}

The clients' needs are exactly embodied in the information provision, reservation, update and query, which requires the database structure function to fully manipulate various 
information input and output. Collecting basic data, data structure and data processing procedures to make a detailed data dictionary to lay a foundation of the specific design .

Through the above analysis of the system function, satisfying the demand of this system ,there are several summarized requirement information as following:

1. This system mainly includes the project management, the product management and the manufacturer management.

2. The bidding equipment in the project basically should be classified, each category includes some products.

3.Each manufacturer is producing its own products, through the product to participate in a project bid. A manufacturer can produce more than one product, or even more than one type product. Each product should be given a quotation in the bid invitation.

4.Each product corresponds to a product category, a category can have more than one product. One quotation corresponds to one or more products, and one product is correspond to one or more quotations..

5. each item of the tender equipment has one or more than one product categories, a category can correspond to multiple projects. After the above functional analysis and demand summary, considering the expansion of the function in the future, the designed data items and data structure are shown below.

(1) The project information, data items include project name, project time, total project cost, units responsible for the project and the description for the content of the project, etc.

The information of the device type, the data item includes type name and a type description.

(3) The manufacturer's information: data items includes the manufacturer's name,the headquarter address, registered establishment time, registered address, registered fund, the name of the legal representative, the legal representative's duty, the nature of the enterprise, the branch offices, the manufacturer's offices in china and the files for agent's representatives.

(4) product information: data items includes the product name, the manufacturer's ID, the category ID and product instructions

The quotation information: data items includes the total price of equipment, spare parts and total price of special tools, technical service price, the total price of elected item, the supporting cost of the project, the domestic total bid price, the bid bond, the delivery date and so on.

\section{System design}

Overall system design. Features of system design

Function modules: through the division of functions, the huge system functions are decomposed and simplified, then organizing them into different modules, thus improves the development efficiency of the system greatly and increases the reusability of the code. First, the system is divided into two functional modules, one is the user interface, one is the management end interface. This can achieve the separation between the user and the management,making the features more clear. Secondly, the division of the two modules' function is detailed.. User's interface is the inquiry for vendor, product, project, category and so on; management interface can be divided into the functional modules for manufacturers, 
products, projects, categories and other entities to add, delete, modify and other functions. Each function is independently designed as a separate module, which facilitates the system's invocation.

Three layer structures' design: the system adopts three layers of structure design, namely logical structure of program points for the user interface layer, mainly geared to the needs of users and information's management, business logic processing layer and data storage layer. The user's interface layer is the management interface of the bid invitation system, including the interface of the user's direct contact and the information management interface of the administrator contact directly. The business logic processing layer is the a layer connected the logical relationship between the database and the interface of the front desk.. The database is the data storage layer, the main function is to store the entire data resources for the system. Three layers are also independent on the actual physical structure, the business logic processing layer is implemented by using JavaBeans, user interface and logic are separate, the safety, maintainability ,reuse and extension of the system are greatly improved.

Object - oriented design: the code of this system is written in Java language, and a notable feature of Java language is the design language of object - oriented. System will project, products, manufacturers, such as the types of messages are encapsulated into the corresponding class, also each have corresponding to their operations, thus increasing the safety and logic of the system scalability. The system in a public class to create a database connection pool, with the public nature of abstract entities into a single class, such as project, vendors, products, entity class package into categories, the relationship between the project and product, projects, products, Manufacturers Association class, front desk management products, manufacturers and project, category are encapsulated into a class, backstage management products, manufacturers and project, category are encapsulated into classes.

Division of function modules

The specific functional blocks are partitioned, as shown in Fig.7, 8. 


\begin{tabular}{|c|c|c|c|c|c|c|c|c|c|}
\hline & & & & On-line & & & & & \\
\hline & & $\begin{array}{l}\text { duct } \\
\text { rmation } \\
\text { ry }\end{array}$ & $\begin{array}{l}\text { Vendor } \\
\text { information } \\
\text { query }\end{array}$ & & $\begin{array}{l}\text { Project } \\
\text { informati } \\
\text { query }\end{array}$ & & $\begin{array}{l}\text { Comp } \\
\text { inforn } \\
\text { query }\end{array}$ & $\begin{array}{l}\text { rehensive } \\
\text { Iation }\end{array}$ & \\
\hline $\begin{array}{l}\text { Category } \\
\text { information } \\
\text { query }\end{array}$ & $\begin{array}{l}\text { Category } \\
\text { product } \\
\text { query }\end{array}$ & $\begin{array}{l}\text { Product } \\
\text { details }\end{array}$ & $\begin{array}{l}\text { Basic } \\
\text { information for } \\
\text { manufacturers }\end{array}$ & $\begin{array}{l}\text { Vendor } \\
\text { details }\end{array}$ & $\begin{array}{l}\text { Basic item } \\
\text { information }\end{array}$ & $\begin{array}{l}\text { Project } \\
\text { details }\end{array}$ & $\begin{array}{l}\text { Query } \\
\text { project } \\
\text { inform- } \\
\text { ation }\end{array}$ & $\begin{array}{l}\text { Query } \\
\text { vendor } \\
\text { informati } \\
\text {-on }\end{array}$ & $\begin{array}{l}\text { Query } \\
\text { product } \\
\text { informa } \\
\text {-tion }\end{array}$ \\
\hline
\end{tabular}

Fig. 7 Customer interface system function module 


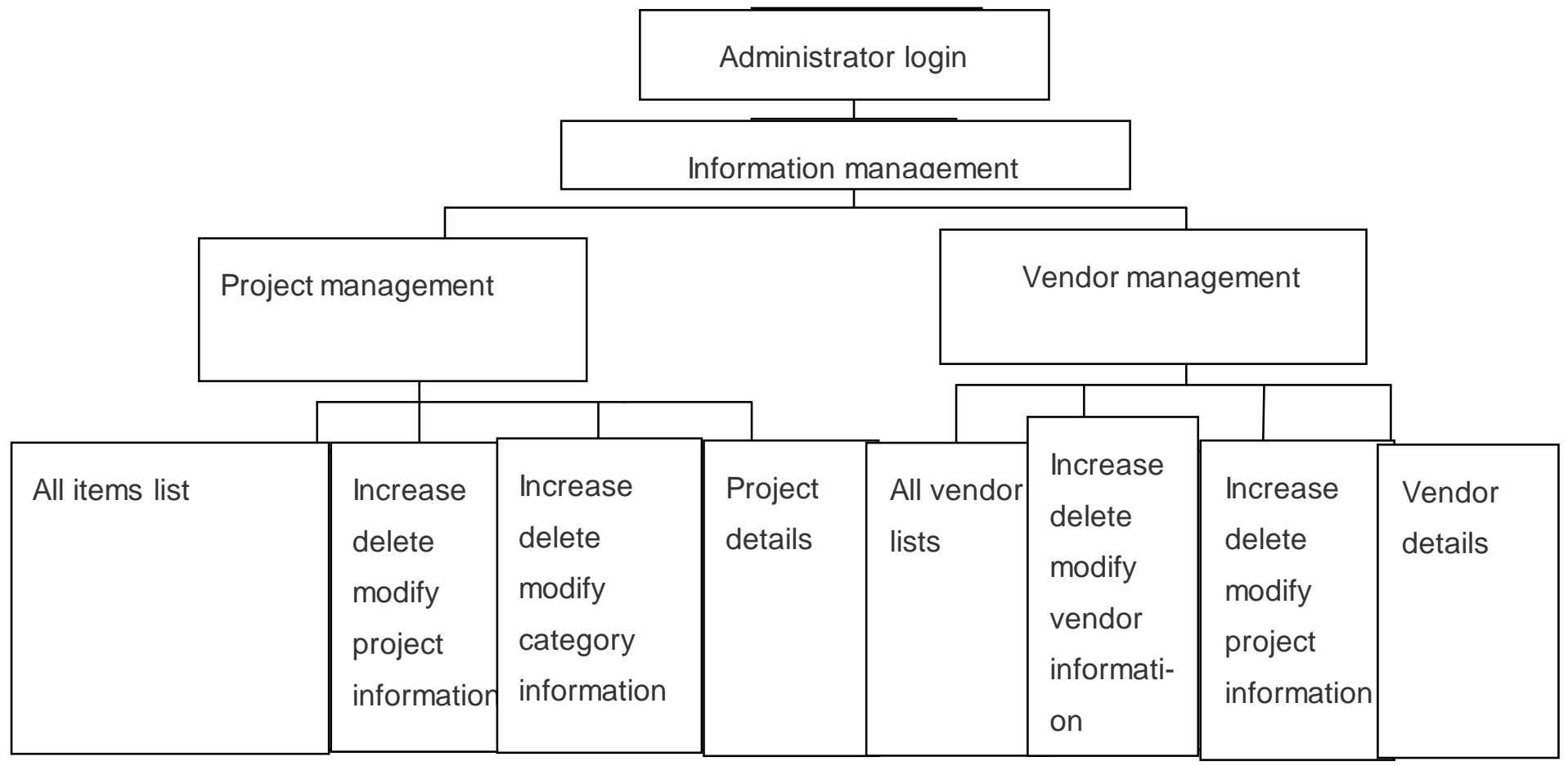

Fig. 8 Management interface function module

System structure design

Overall structure design, as shown in Fig. 9. 


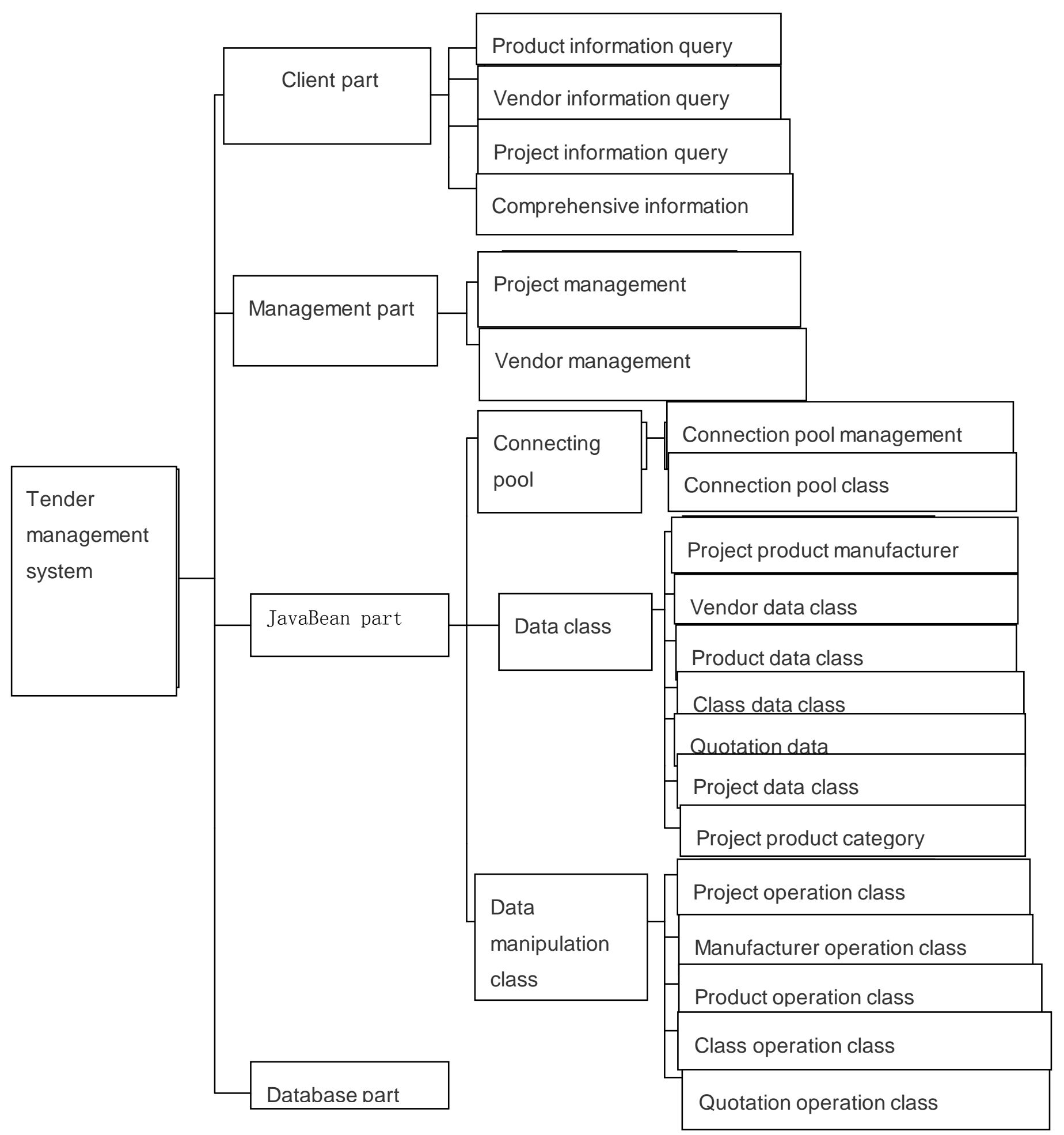

Fig. 9 System structure design chart

Design the system in detail. Through the detailed division of system and functional modules .further completing the the detailed design for system. There are two ways to query information and search for users to enter the interface.Entering the corresponding information interface, as shown in Fig. 10.

User flow chart: 


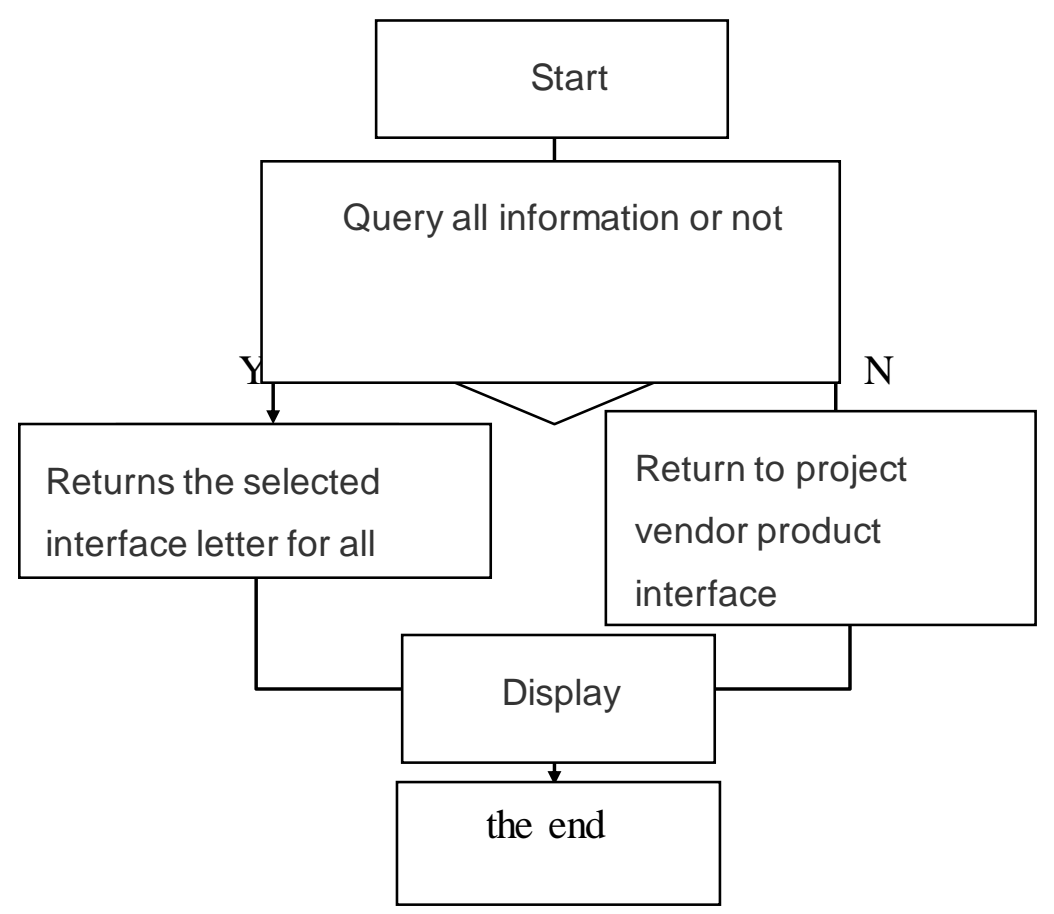

The process of the management is more complex, the main items, manufacturers, products, categories of add, delete, modify, etc., if the corresponding operation error, then return the error message.

Detailed management of the flow chart, as shown in Fig.11. 


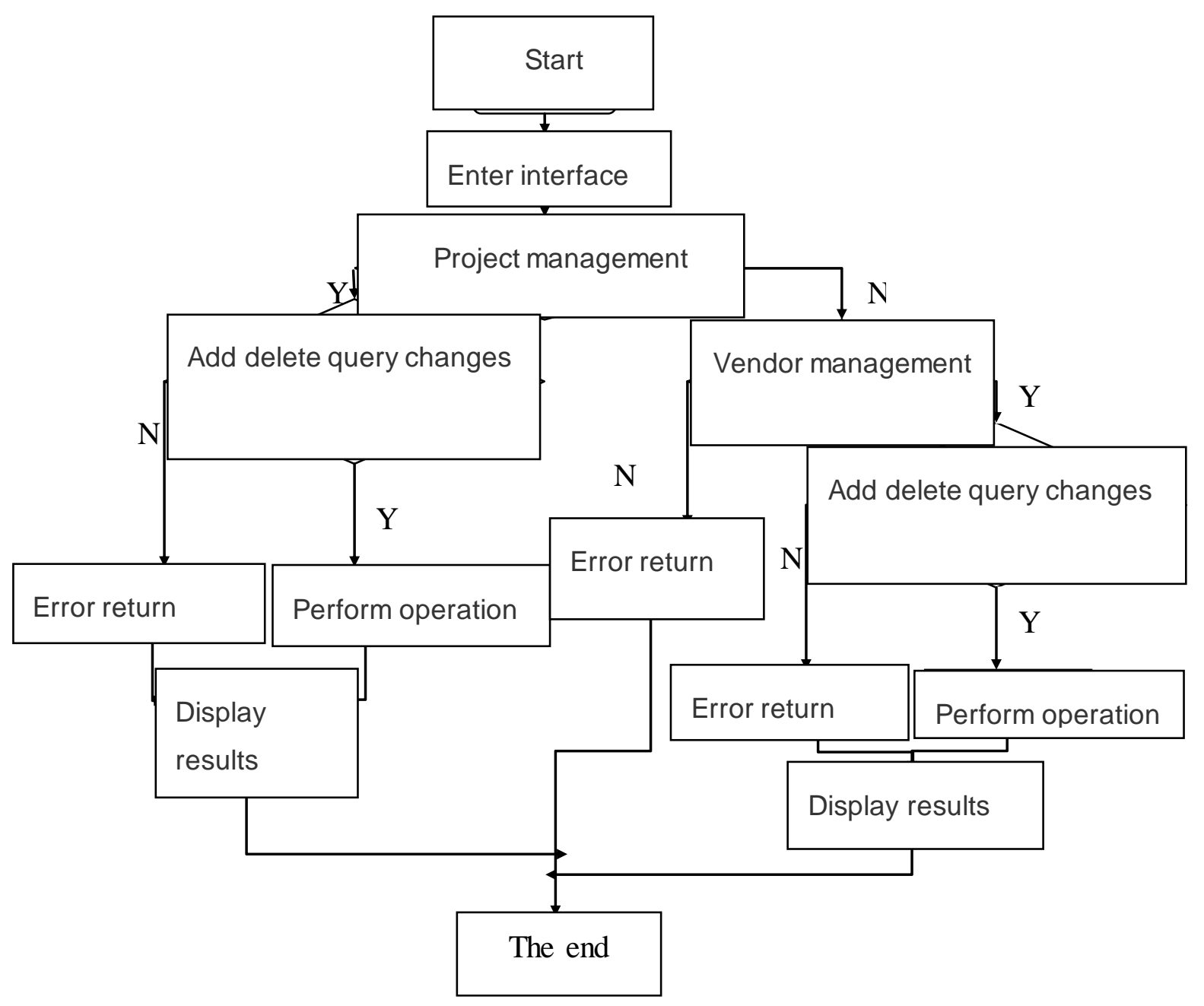

\section{System testing}

The ultimate goal of the testing phase is to find and eliminate the hidden errors in the software as much as possible, and eventually to give a high-quality software system to users.

The system tests mainly carry out the black box test, the function test, the white box test, the structure test. The test should start with a small scale and gradually carry out the large-scale test. Firstly, the emphasis is on testing the individual program module, and the further testing focus on the integrated module cluster to find the error, and finally to find the error in the whole system. This system mainly carries on the black box test. Black box test tries to discover the following types of error: function is incorrect or missing function; interface errors; data structure errors, or external database access error; error performance; the initialization and termination errors.

The code is traceable to the user's needs. In the module function of the end users, to meet the needs of users .Let them can quickly search the vendor item information; on the management side, function module is mainly to add, modify, delete and other operations. 


\section{Conclusions}

The main functions of the system include read and operate the information on the tender, so design two functional interface in response to accomplish these functions, one is the user 's interface, and another is the management's interface. User interface's feature is mainly query for products, manufacturers, project queries, and comprehensive query. Comprehensive inquiry is mainly through the input of keywords to search related information. The management interface includes the management of the project and the manufacturer. Project management is to complete the addition and removal of the project, and can through the control button to go back home or last page or enter into the page directly. The adding item for adding points are item name, time, responsibility for unit, total cost and project description. Vendor management is primarily to add, delete manufacturers. Add new vendors is mainly to add name, address of the headquarters, registration, creation time, registered address, registered funds, legal name, position, the nature of the enterprise, branches, company, branch office contact sheets, manufacturers in China office or agency on behalf of the data and other information.

\section{Acknowledgements}

This work was financially supported by project of Technology Department of Jiangxi Province [No 20143BBM26048]and project of Jiangxi University of Technology [No. xtcx201312].

\section{References}

[1] Kevin Wittmer.EPerl:PERL,C++ , and Java .The World Software Development, 2005,17(1):1 $\sim 5$

[2] Written by MARY Campione Kathy Walrath Alison Huml ,translate by Ma Zhaohui,Chen Meihong . Java Language guide. Third edition. Beijing:Press of machinery ind ustry,2003:3 5

[3] Ma Yongheng, Xiong Qianxing, Yang Jine, Li Yuqiang, Che Lei,Yang Jian.Research on the conversion service of Java development data.Computer Engineering, 2006, 32(1):267 269

[4] Liu Tao,Lou Xinghua.SQL Server 2000Database system development instance navigation .first edition.Beijing:People's Posts and Telecommunications Press,2004:6 15

[5] Abraham Silberchatz,etc.Database system concept.first edition. Beijing:Press of machinery industry, 2003:5 10

[6] Sun Weiqing,Li Hongcheng,etc. Auspicious solution for Tomcat and Java's Web development technology.First edition.Beijing: Electronic industry press,2004:1 10

[7] Geng Yixiang.Jsp basic tutorial.First edition. Beijing:Tsinghua University press,2004:12 23

[8] Zhang Haifan.Software engineering[M].First edition.Beijing : People's Posts and Telecommunications Press, 2002:2 5 